\title{
O uso de dicionários escolares em produções textuais de alunos do ensino fundamental
}

\author{
Rosane Maria Bolzan \\ Universidade Estadual de Londrina \\ rosanebolzan@yahoo.com.br
}

\section{Resumo}

Esta pesquisa é de natureza empírica, de cunho qualitativo-interpretativo, além de configurar-se como colaborativa. Utilizaram-se pressupostos teóricos advindos de estudos da Lexicografia e da Metalexicografia Pedagógica (WELKER, 2006, 2008; KRIEGER, 2006, 2007; LEFFA, 2000; COROA 2011) e da sua relação com a Linguística Aplicada. Objetivou-se investigar os efeitos do uso orientado de dicionários escolares no incremento de produções textuais de alunos de uma turma de quinto ano do ensino fundamental. Houve uma intervenção no grupo de alunos, denominado Grupo de Experimentação (GE), com um trabalho sobre o uso de dicionários escolares (Tipos 1,2 e 3) em produções textuais. Na coleta de dados foram incluídos, de cada um dos 25 alunos de uma turma de uma escola municipal de Garopaba/SC, três textos com diferentes intervenções (dos colegas, dos professores e dos dicionários), produzidos durante o segundo semestre letivo de 2011. Os resultados da pesquisa apontaram que a maioria dos alunos (23) que constituíram o GE aumentou o vocabulário em textos reescritos, bem como melhorou na estruturação e no detalhamento dos elementos narrativos. Os textos reescritos com a intervenção dos dicionários resultaram mais detalhados e elaborados, por meio do uso do vocabulário estudado durante os processos de interação entre professor/aluno, aluno/aluno, aluno/dicionários. Neste artigo, exemplifica-se o trabalho com a amostra de análise de um aluno do GE.

Palavras-chave: Metalexicografia Pedagógica. Dicionários escolares Produção textual.

\section{The use of dictionaries in writings of elementary school students}

\begin{abstract}
:
This is an empirical and a qualitative-interpretive research, and set up as collaborative. We used theoretical assumptions arising from Lexicography, Pedagogical Metalexicography (Welker (2006, 2008), Krieger (2006, 2007), Leffa, (2000), Coroa, (2011)), and its relationship with Applied Linguistics. This study aimed to investigate the effects of an oriented use of school dictionaries in the increment of textual productions of elementary school students in a class of the fifth year of an elementary school. There was an intervention in a student group, called Group of Experimentation (GE), whose aim was to teach how to use school dictionaries (Types 1,2 and 3) in textual productions. Data collection included three texts each student with different interventions (from peers, teachers and use of dictionaries) in a class of 25 students during the second semester of 2011 in a municipal school in Garopaba / SC. The data showed that most of the students (23) of the GE increased vocabulary in rewritten texts, and improved the structure and detail of the narrative texts. The texts rewritten with the assistance of dictionaries resulted more detailed and elaborate. In this article, the experience made is exemplified by the analysis of one of the textual production did by one of the students.
\end{abstract}

Keywords: Pedagogical Metalexicography. School dictionaries. Textual production. 


\section{INTRODUÇÃO}

O dicionário é uma obra que não é apresentada para a quase totalidade das pessoas quando ainda frequentam o ensino fundamental e, muito menos, após ele, no ensino médio, e níveis subsequentes. Pareceria normal uma obra com especificidades próprias (uso de siglas, palavras dispostas em colunas, em ordem alfabética, normalmente, com destaques e números) ser introduzida aos consulentes em uma etapa de vida em que o indivíduo é mais dependente e carente de informações do professor, como no ensino fundamental. Apesar dessa necessidade, isso acontece excepcionalmente, quando acontece.

Em determinado momento, se percebe que essa obra já faz parte do contexto da vida da escola, das pessoas em suas casas, mas com um uso precário e limitado. Em geral, os alunos têm dificuldade para compreender as informações de um dicionário e, muitas vezes, não encontram o que procuram nessa obra. Esse quadro se repete com os professores, pois, de modo geral, não receberam instruções durante a sua formação para usar esse tipo de obra em sala de aula. Como consequência, não têm condições de ensinar sobre sua organização e manuseio, enquanto ferramenta útil e necessária no processo de ensino e de aprendizagem.

Para o senso comum, o dicionário isola palavras e possui uma compilação das mais antigas, o que pode lhe atribuir uma imagem de obra desatualizada. Nesta pesquisa, considera-se o dicionário com uma visão que se atualiza pela interação. Isso significa que os itens lexicais que o constituem se relacionam intrinsecamente com a sociedade, o que constitui um movimento interativo e de atualização: eles nascem do social, vão para os dicionários para continuarem a interagir com as pessoas, influenciando-as com suas informações e sendo aplicados, novamente, nos contextos de uso. Muitos itens lexicais caem em desuso pelo movimento vivo da língua, o que não significa que não têm mais importância, pois continuam a representar uma dada situação temporal e social. Portanto, continuam a representar a história de um povo, a sua identidade, e estarão à disposição de todos que procuram por informações e conhecimento, seja do passado ou do presente.

Segundo Krieger (2007, p. 298), o dicionário tem uma função pedagógica inquestionável. Por essa razão, ele pode ser uma ferramenta a mais no desenvolvimento da leitura, da produção textual e da análise linguística. Também pode colaborar na leitura proficiente, na escrita, na realização de análises críticas da língua e de suas variações sociolinguísticas e no conhecimento do vocabulário.

Este estudo sobre o dicionário como ferramenta de consulta pedagógica que pode incrementar o vocabulário dos alunos em produções textuais, bem como melhorá-las em aspectos gramaticais e de conteúdo, justifica-se tendo em vista os seguintes fatos:

- primeiro, segundo Welker (2008, p. 295-356), foram realizadas poucas pesquisas sobre o uso de dicionários escolares. Além disso, tais pesquisas contaram com um número pequeno de informantes e não verificaram nem o uso efetivo, nem o efeito do uso de tais obras, o que denota uma lacuna nas pesquisas que contemplam o uso do dicionário em sala de aula. Outrossim, Leffa (2011, p. 124) enfatiza que somente o uso sistemático do dicionário pode levar à aprendizagem e ao prazer de descobrir nas palavras as promessas de sentido que elas escondem. Krieger (2007, p. 298) reitera o estatuto de obra de referência linguística e pedagógica do dicionário e afirma que a escola não prescinde do dicionário, seja na língua materna ou estrangeira, mesmo não explorando seu potencial didático. Esse quadro mostra, conforme a autora, “[...] uma história para ser escrita”. Dessa forma, espera-se contribuir para começar a escrever sobre ela;

- segundo, Welker (2006, p. 251) afirma que, nas poucas pesquisas feitas sobre o uso, os sujeitos não tiveram que escrever redações (textos), de modo que não há elementos para avaliar o efeito do uso de dicionários nas situações de produção escrita. O autor esclarece que, "Se um dicionário não fornece apenas definições, e sim também informações gramaticais (e outras), é porque ele está previsto não somente para a recepção como também para a produção de textos, pois para compreender textos não se precisa de tais informações" (WELKER, 2008, p. 329);

- o terceiro fato se refere à importância dada pelos Parâmetros Curriculares Nacionais (PCNs) ${ }^{1}$ ao en- 


\section{Extensio $\mid$ Dossier}

sino da língua materna, orientando as propostas didáticas que se organizam a partir do texto como unidade básica de trabalho, já que o domínio da língua, oral e escrita, torna-se fundamental para a participação social efetiva do homem (PCNs, 1997, p. 15-21);

- o quarto fato que justifica o desenvolvimento de um trabalho que vise ao incremento da produção escrita de alunos mediante o uso de dicionários escolares é que se verifica que a maioria dos alunos que concluem o ensino médio e ingressam nas universidades apresenta dificuldade para se expressar por escrito com propriedade vocabular, entre outros problemas.

Com o uso de dicionários, o universo vocabular do aluno poderá ser expandido, e o trabalho de consulta à obra de forma sistematizada pode colaborar para que se vejam as produções textuais como fruto de trabalho permanente da linguagem, ou seja, como um processo com "movimentos" de construção e reconstrução por meio da reescrita de significados que acompanham o desenvolvimento do nosso acervo lexical. Segundo Coroa (2011, p. 71-72), ao assimilar novos significados por meio de dicionário, o aluno poderá usá-los na busca de maiores conhecimentos e aprenderá a conhecer melhor os processos significativos da linguagem e as implicações de suas escolhas linguísticas.

Para a efetivação da pesquisa, determinaram-se objetivos, os quais são discriminados em:

- apresentar o dicionário escolar, de forma sistematizada, como instrumento didático-pedagógico que pode contribuir para ampliar o domínio do vocabulário, oportunizando a aprendizagem de novos itens lexicais e possibilitando o seu emprego em produções textuais;

- investigar os efeitos do uso orientado de dicionários escolares no incremento de produções textuais de alunos do ensino fundamental, quer seja em continuidade ou em unidade;

- propor o uso de dicionários escolares em produções textuais como um auxílio na construção de processos significativos de interação da linguagem, que norteiam o desenvolvimento do acervo lexical e que passam pela escrita e reescrita.

- possibilitar aos alunos a exploração de dicionários escolares diferenciados, para que, além de perceberem semelhanças e diferenças entre eles, os vejam também como obras que promovem reflexão linguística.

Buscando reconhecer nos estudos da Lexicografia a questão da influência do dicionário na produção textual e suas implicações no contexto educacional, defendeu-se, neste trabalho, que o uso dessa obra como instrumento pedagógico pode melhorar e implementar o vocabulário dos consulentes, verificando essa melhora em textos produzidos pelos estudantes.

\section{MATERIAL E MÉTODOS}

Esta pesquisa é empírica, qualitativo-interpretativa, além de configurar-se como colaborativa. Situa-se na área de concentração Linguagem e Significação, do Programa de Pós-Graduação em Estudos da Linguagem, da Universidade Estadual de Londrina (UEL), na linha de pesquisa Descrição e Análise Linguísticas.

Em um primeiro momento, houve um trabalho com 24 professores da Rede Municipal de Garopaba/ SC, município que possui um campus do Instituto Federal de Santa Catarina (inaugurado no ano de 2010). Ofertou-se um curso sobre o uso de dicionários escolares em sala de aula, no ensino fundamental.

A escolha desse grupo de professores relacionou-se ao fato de o Instituto Federal de Santa Catarina oferecer um curso de formação inicial e continuada para professores da Rede de Ensino Fundamental do município de Garopaba/SC, incluindo nesse projeto 20 horas dedicadas à disciplina de Português. A pesquisadora, como docente da área de Português do LF/SC, foi incumbida de ministrar essas aulas. ${ }^{2}$ Concluiu-se

1 Elaborados pelo Ministério da Educação e Cultura (MEC), atendendo ao artigo $9^{\circ}$ da Lei no 9.394 , sancionada em 20 de dezembro de 1996, Lei de Diretrizes e Bases da Educação Nacional (LDB). 
que isto possibilitaria uma oportunidade de propor um curso de extensão sobre o uso de dicionários em sala de aula para um grupo já formado de professores e, desta forma, iniciar o projeto de pesquisa propriamente dito. Na sequência, esses professores poderiam trabalhar com seus alunos o conteúdo do curso de extensão no ensino fundamental. ${ }^{3}$ Interessa neste artigo descrever o segundo momento da pesquisa.

Em um segundo momento, dois professores colaboradores da pesquisa, da Escola Municipal de Ensino Fundamental Pinguirito, de Garopaba/SC, participaram do trabalho de coleta de dados com suas respectivas turmas: uma turma constituiu o Grupo de Controle (GC), e a outra, o Grupo de Experimentação (GE). No primeiro grupo (GC), o dicionário foi utilizado de acordo com a abordagem habitual do professor da turma, ou seja, sem um enfoque diferenciado, já que o professor não participou do curso de formação ${ }^{4}$; em relação ao segundo grupo (GE), pressupôs-se que o professor, após seguir o curso sobre o uso de dicionários, estaria mais preparado e consciente para ensinar a seus aprendizes a fazerem uso constante e sistemático de dicionários em aula.

O trabalho do professor do GE foi acompanhado semanalmente, precisamente durante dois dias da semana, e houve uma programação inicial de intervenção da pesquisadora na sala de aula do GE, com o desenvolvimento de atividades voltadas ao dicionário, bem como o incentivo à sua consulta.

Nesse acompanhamento, as produções textuais do GE foram analisadas pelo período de um semestre, na tentativa de averiguar se o uso do dicionário interferiu nas produções textuais dos alunos no que tange à fixação do vocabulário, bem como ao incremento de forma e conteúdo à escrita e também à melhora dos textos em aspectos lexicais e gramaticais, em organização, acréscimo de ideias e complementação (o quê, quando, onde, quem, como, por quê, de que forma?). Para a produção de textos, contemplaram-se narrativas, por fazerem parte do mundo da criança através de histórias de ficção, da família, da comunidade, da escola, do município, e por serem já trabalhadas no meio escolar e conhecidas pelas crianças.

Estabeleceu-se o número de três versões de textos para a primeira coleta de dados, incluindo a leitura dos colegas como avaliadores da escrita, a intervenção de diferentes dicionários e a abordagem escrita e oral dos professores. Para a segunda coleta de dados no GE, pensou-se em um trabalho que abordou duas versões, seguindo o número habitual, normalmente contemplado em sala de aula. ${ }^{5} \mathrm{Com}$ o desenvolvimento dessas etapas, tratou-se de um trabalho tendo a visão do texto como um processo, como trabalho permanente, mediado por autores-leitores e por dicionários, e não como um produto acabado.

\subsection{A escolha dos dicionários}

A seleção dos dicionários se deu levando em consideração a avaliação da Secretaria de Educação Básica (SEB/MEC) para o Programa Nacional do Livro Didático (PNLD) /Dicionários de 2006, ou seja, através

2 O Instituto Federal de Santa Catarina (IF-SC) é uma instituição pública federal vinculada ao Ministério da Educação (MEC) por meio da Secretaria de Educação Profissional e Tecnológica (SETEC). Tem sede e foro em Florianópolis, com autonomia administrativa, patrimonial, financeira, didático-pedagógica e disciplinar. A missão do IF-SC é desenvolver e difundir conhecimento científico e tecnológico, formando indivíduos capacitados para o exercício da cidadania e da profissão, e tem como visão de futuro consolidar-se como centro de excelência na educação profissional e tecnológica no Estado de Santa Catarina.

3 Este primeiro momento foi detalhado em um artigo escrito para Eutomia, revista on-line de Literatura e Linguística, intitulado "A formação docente em Lexicografia e a realidade sobre o trabalho com dicionários em sala de aula", Recife, 8. ed., ano IV, p. 323-345, dez/2011. Autoria de Rosane Maria Bolzan e Adja Balbino de Amorim Barbieri Durão.

$4 \quad$ Este grupo não foi contemplado neste artigo. Na tese da doutoranda segue a análise dos textos do GC.

5 A segunda coleta de textos e respectivas análises não foram incluídas neste texto pela limitação de espaço. A pesquisa completa está contemplada na tese da doutoranda intitulada "O uso de dicionários escolares em produções textuais do Ensino Fundamental" (em processo de qualificação). 


\section{Extensio $\mid$ Dossier}

da aprovação dos melhores dicionários, segundo critérios adotados pelo MEC naquele ano. ${ }^{6}$ Além disso, priorizaram-se dicionários diversificados, para que os alunos pudessem ter a oportunidade de conhecer diferentes propostas lexicográficas e ainda pudessem perceber que há diferentes tipos de dicionários, formando senso crítico sobre os mais apropriados à sua faixa etária e de acordo com suas necessidades de uso. Conforme Krieger (2006, p. 246):

O conjunto de parâmetros e critérios adotados permitiu estabelecer, para cada tipo, o perfil de obra capaz de contribuir satisfatoriamente para os diferentes aspectos das fases de ensino/aprendizagem previstas, como o acesso ao mundo da escrita, a aquisição de vocabulário, a competência de leitura e escrita, entre outros.

Quanto aos títulos dos dicionários, foram escolhidos os seguintes:

a) Aurelinho: Dicionário Infantil Ilustrado da Língua Portuguesa. Editora Positivo (Tipo 1).

b) Meu primeiro Dicionário Houaiss. Objetiva (Tipo 1).

c) Caldas Aulete Dicionário Escolar da Língua Portuguesa: Ilustrado com a Turma do Sítio do Pica-Pau Amarelo. Nova Fronteira (Tipo 2).

d) Dicionário Ilustrado de Português. Ática (Tipo 2).

e) Saraiva Júnior: Dicionário da Língua Portuguesa Ilustrado. Saraiva (Tipo 2).

f) Moderno Dicionário Escolar. Moderna (Tipo 2).

g) Dicionário Júnior da Língua Portuguesa. FTD S/A (Tipo 3).

Tomada a decisão sobre que série trabalhar, selecionaram-se dois dicionários do tipo 1 como forma de apresentação mais simplificada de dicionários, com uma linguagem mais infantil e acessível, além de prazerosa. Foram escolhidos quatro dicionários do tipo 2 pela recomendação da avaliação do MEC (PNLD/2006) para essa faixa etária (duas séries finais do primeiro segmento do ensino fundamental) e que registram um número maior e mais variado de palavras. O dicionário do tipo 3 foi escolhido por representar um desafio maior aos alunos, pois contém um número maior de verbetes e informações mais aprofundadas do que os dois primeiros tipos, compatível com necessidades requeridas pelas atividades de leitura e de produção textual. Além desses critérios, considerou-se uma escolha progressiva no nível dos dicionários, com a finalidade de adaptar os alunos a esse tipo de obra, já que estavam acostumados a trabalhar apenas com minidicionários. ${ }^{7}$

6 A proposição do MEC é de três acervos e de três tipos de dicionários. Acervo "A" - voltado para alunos do ciclo inicial de alfabetização (dois ou três primeiros anos), envolvendo crianças de 6 a 8 anos, e engloba dicionários de dois tipos: o primeiro tipo tem um número de verbetes que varia entre 1.000 a 3.000 palavras, e o segundo tipo registra um número maior de verbetes, entre 3.500 e 10.000. O Acervo “B” está direcionado para o aluno das duas séries finais do primeiro segmento do Ensino Fundamental. O objetivo dele é familiarizar o aluno com o gênero lexicográfico dos dicionários-padrão. Visando a uma transição tranquila do aluno para o dicionário de uso geral, o Acervo "B" ainda inclui dois dicionários do segundo tipo, mas a maioria dos dicionários do Acervo "B" é de um terceiro tipo. No Acervo "C", quase todos os dicionários têm características típicas de minidicionários de uso geral e registram entre 19.000 e 35.000 palavras; possuem uma estrutura de verbete mais complexa que os demais dicionários de ambos os acervos; trazem um maior número de informações linguísticas sobre as palavras registradas e usam uma linguagem simples, mas impessoal e nem sempre diretamente acessível para o aluno, por isso compõem um terceiro acervo distribuído para as séries/anos finais. Maiores informações em <http://portal. mec.gov.br>.

7 Para se obter essa informação, contatou-se a professora da turma durante o curso de formação de professores. 


\subsection{Procedimentos da coleta dos dados}

Nesta seção, apresentam-se os detalhes da coleta de dados do GE. Também se detalham as características gerais sobre os sujeitos da pesquisa, bem como o procedimento de trabalho com os textos dos alunos.

\subsection{Grupo de Experimentação (GE)}

Trabalhou-se com 25 alunos do $5^{\circ}$ ano 01 da Escola Municipal de Ensino Fundamental Pinguirito, localizada no município de Garopaba/SC, durante o segundo semestre letivo de 2011. O trabalho, que iniciou no mês de agosto e terminou em novembro, foi realizado nessa própria escola.

O grupo compunha diferentes faixas etárias: 11 alunos com 11 anos, 10 com 10 anos, 3 alunos com 12 anos e 1 com 13. A maioria dos alunos era do sexo masculino, especificamente 18, e apenas 7, do sexo feminino. Não havia alunos repetentes na série e sempre estudaram em escola pública.

A coleta de dados iniciou após uma preparação dos alunos feita pela pesquisadora com o objetivo de apresentar-lhes o projeto de pesquisa, além de iniciá-los na exploração e manipulação dos dicionários.

A primeira coleta de textos passou por três fases. Solicitou-se a produção de uma narrativa, após a leitura e discussão de um texto jornalístico selecionado pela professora da turma sobre a situação dos engenhos de farinha de mandioca de Garopaba e da audição de histórias familiares sobre lendas e folclore da região. ${ }^{8}$ Nessa primeira versão, eles não poderiam usar os dicionários para consulta. Deveriam escrever por si próprios, a partir da preparação que obtiveram.

No caso desta pesquisa, foram empregadas revisões individuais, colaborativas e orientadas, uma vez que se desejava obter dados que mostrassem que, por meio da interação entre aluno-aluno, aluno-professor, aluno-dicionários, o aluno tomaria consciência de que seu texto se constrói pelo trabalho e pela avaliação constantes. Além disso, poderia perceber que a escrita passa por um processo de reescrita, de reflexão e de interação com quem está envolvido no processo de ensino-aprendizagem. Dessa forma, os estudantes poderiam ir além das sugestões oferecidas pelo professor, no momento da reescrita e da consulta aos dicionários. Com o manuseio e uso constante dessas obras, poderiam tomar consciência do papel dos dicionários nas suas produções e do quanto se pode aprender sobre a língua consultando essas obras.

Depois de uma semana, os textos foram trabalhados novamente pelos alunos. Dessa vez, os alunos trocariam os textos dois a dois. Cada um avaliaria a produção do colega fazendo observações abaixo do texto sobre possíveis problemas detectados (ortografia, acentuação, paragrafação, observando a estrutura do texto narrativo e respondendo às questões: quem, o quê, onde, quando, como e por quê?). Após realizarem as modificações na segunda versão da narrativa levando em consideração as observações dos colegas, os alunos deveriam passar a limpo o novo texto e entregá-lo aos professores.

Depois de duas semanas, os textos da segunda versão foram devolvidos aos alunos com a intervenção da pesquisadora e do professor da turma, em forma de bilhete, sugerindo modificações de estrutura narrativa, de grafia, de significados de palavras, de acentuação, de concordância verbal e nominal, de repetição de palavras, de separação de sílabas, de paragrafação, de pontuação e de outros problemas detectados na leitura.

Para a elaboração da terceira versão dos textos, os alunos deveriam utilizar os dicionários, bem como receberiam orientações dos professores, imprescindíveis em se tratando de um público infantil, para que melhor compreendessem o que havia sido recomendado nos bilhetes e para minimizar sua insegurança.

De posse dos produtos de cada fase do GE, partiu-se para a análise dos dados, cujos procedimentos serão explicitados a seguir.

8 Texto jornalístico, lido e refletido, intitulado "Farinha da boa" (15/08/2011), publicado no Jornal da Praia de Garopaba/SC. 


\subsection{Procedimentos da análise dos dados}

Cada aluno do GE recebeu, para identificação, um código de “1” a “25”. Além disso, cada tarefa de escrita e reescrita foi identificada pelos códigos "a", "b" e "c", conforme sua ordem de ocorrência.

Por ser um estudo que ainda não havia sido feito, conforme Welker (2006, p. 251), escolheram-se categorias de análise de narrativas postuladas por Geraldi (1984), com o propósito de demonstrar o processo de reescrita, sobretudo com a intervenção de dicionários.

Iniciou-se a primeira fase de análise, a qual foi baseada em Geraldi (1984, p. 64-67) quando postula que a prática de análise deverá incidir sobre problemas que as narrativas podem apresentar: de estrutura textual e de ordem sintática, morfológica e fonológica.

Analisadas as produções nos aspectos citados acima, iniciou-se a segunda fase de análise das produções, agora na reescrita. Essa etapa consistiu em cotejar as primeiras versões dos textos dos alunos com as segundas, escritas a partir de observações de um colega de aula. Atentou-se para as modificações realizadas com a ajuda dos colegas no papel de leitores.

A terceira fase de análise dos textos consistiu em analisar as modificações feitas a partir do uso dos dicionários e das orientações escritas pelas professoras nos bilhetes.

Após a análise separadamente das três produções, houve o cotejo entre elas para escrever sobre os resultados. A seguir, a amostra de produções textuais do aluno número "18" do GE. ${ }^{9}$

\section{RESULTADOS E ANÁLISE}

Análise ilustrativa da produção textual do aluno "18" do GE. Temática: "Os engenhos de farinha de Garopaba”.

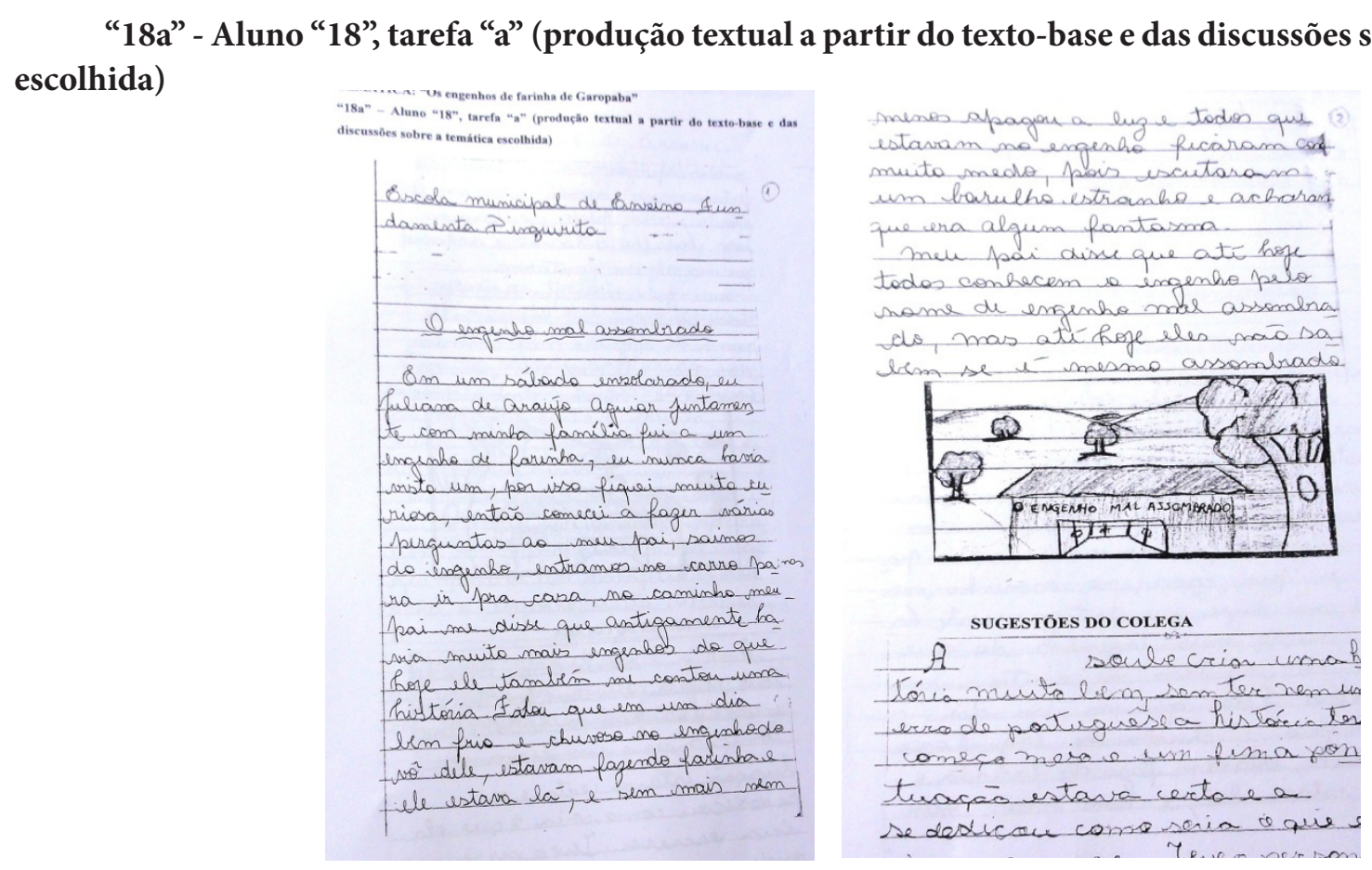

9 Este artigo não comporta a análise completa realizada pela doutoranda, por isso, para demonstrá-la, fez-se um recorte da análise de um aluno do GE. As conclusões foram realizadas sobre o total das produções textuais analisadas (25 alunos) do GE. 
Este aluno apresentou uma linguagem padrão na sua escrita, praticamente em todo o texto. O seu vocabulário chama a atenção por estar num nível mais adequado à formalidade que esse tipo de produção exige, com palavras como: "juntamente", "havia visto". As concordâncias são adequadas em se tratando da linguagem padrão ("havia muito mais engenhos", "saímos do engenho, entramos no carro..."), usa discurso indireto e não contrai preposições, conforme acontece na oralidade ("Falou que em um dia bem frio e chuvoso no engenho do avô dele, estavam fazendo farinha e ele estava...”). Essas características tornam o texto coerente, com uma lógica estrutural e semântica, dando fluidez à leitura. $\mathrm{O}$ aluno também utiliza em seu texto vários mecanismos coesivos, como "juntamente com", "por isso, "então", "que”, "pois", "mas".

$\mathrm{O}$ aluno teve problemas para contar uma história com um acontecimento importante, um clímax e uma resolução para o fato. Fez uma narrativa relatada de forma indireta, contando o que o pai da personagem havia dito.

Destacam-se algumas expressões da oralidade, tais como: "sem mais nem menos", "pra". Aliás, o aluno fez somente dois parágrafos no seu texto, dando a impressão de que não tem noção de como se faz um parágrafo, quando começá-lo e terminá-lo.

O aluno não se atém na descrição das personagens, nem do lugar, não entra em detalhes. Sabe-se que há a personagem narradora, seu pai e seu avô paterno.

Ocorre um problema de concordância verbal logo no início do texto: "eu... juntamente com minha família fui a um engenho de farinha..." (por nós fomos), outro de acentuação em "saimos" (por saímos). O aluno não tem noção de como usar o ponto final, e há vários problemas com as vírgulas, as quais são usadas em momentos errados conforme a gramática padrão ou suprimidas. O título do texto é coerente com a narração do aluno.

\section{“18b" - Aluno "18", tarefa "b" (produção textual com intervenção de um colega)}

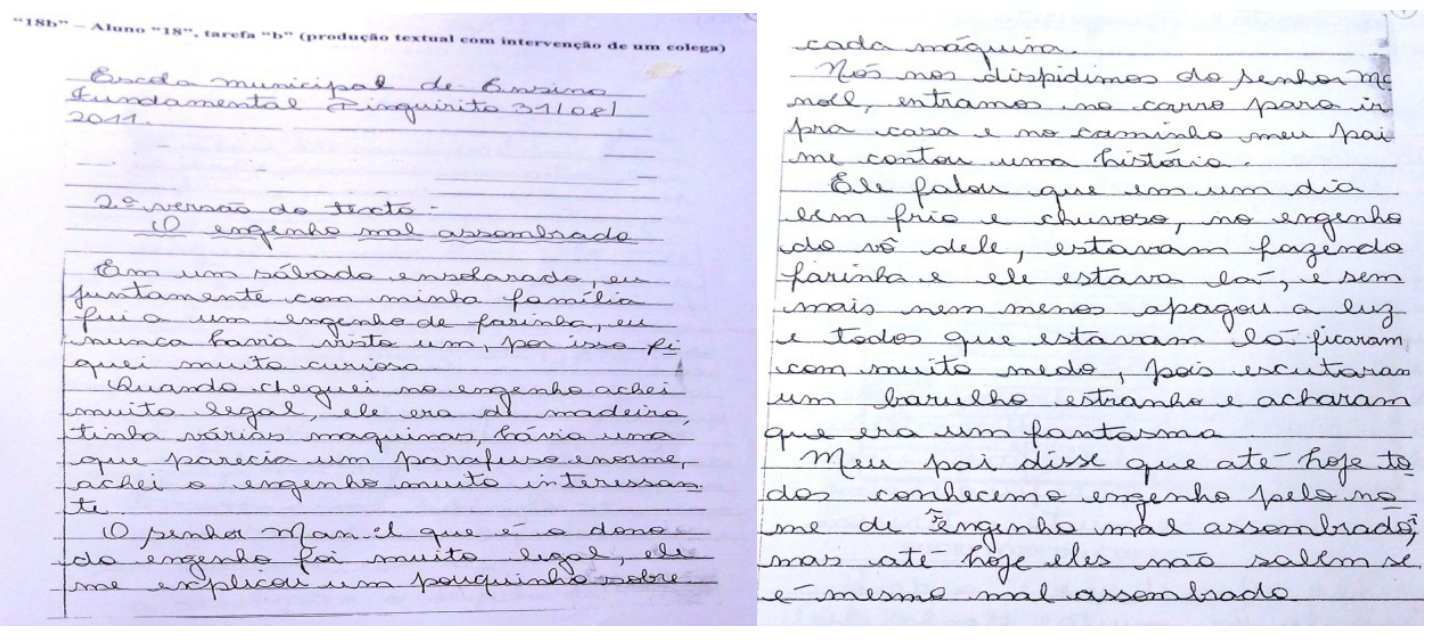

Nesta segunda versão, a aluna fez várias modificações, embora o colega não tenha percebido nenhum problema, pelo contrário, a elogiou: "Ela é uma ótima autora".

A aluna fez seis parágrafos nesta versão e acrescentou ideias, além de conservar as já escritas na versão “a”. Trabalhou para concatenar umas ideias nas outras. Acrescentou uma descrição ao engenho: "era de madeira, tinha várias máquinas, havia uma que parecia um parafuso enorme.... Também acrescentou um personagem chamado "Seu Manuel", que era o dono do engenho. Depois prosseguiu com os mesmos fatos.

Houve alguns problemas com a grafia, como "hávia", "dispidimos", e os problemas com a pontuação continuaram. De forma geral, a aluna escreve dentro da norma padrão e possui facilidade para se expressar, já que para o leitor é fácil entender o que escreveu, a não ser, às vezes, pela falta de pontuação e por seu uso inadequado. 
“18c" - Aluno “18”, tarefa “c” (produção textual com intervenção dos dicionários e dos professores)
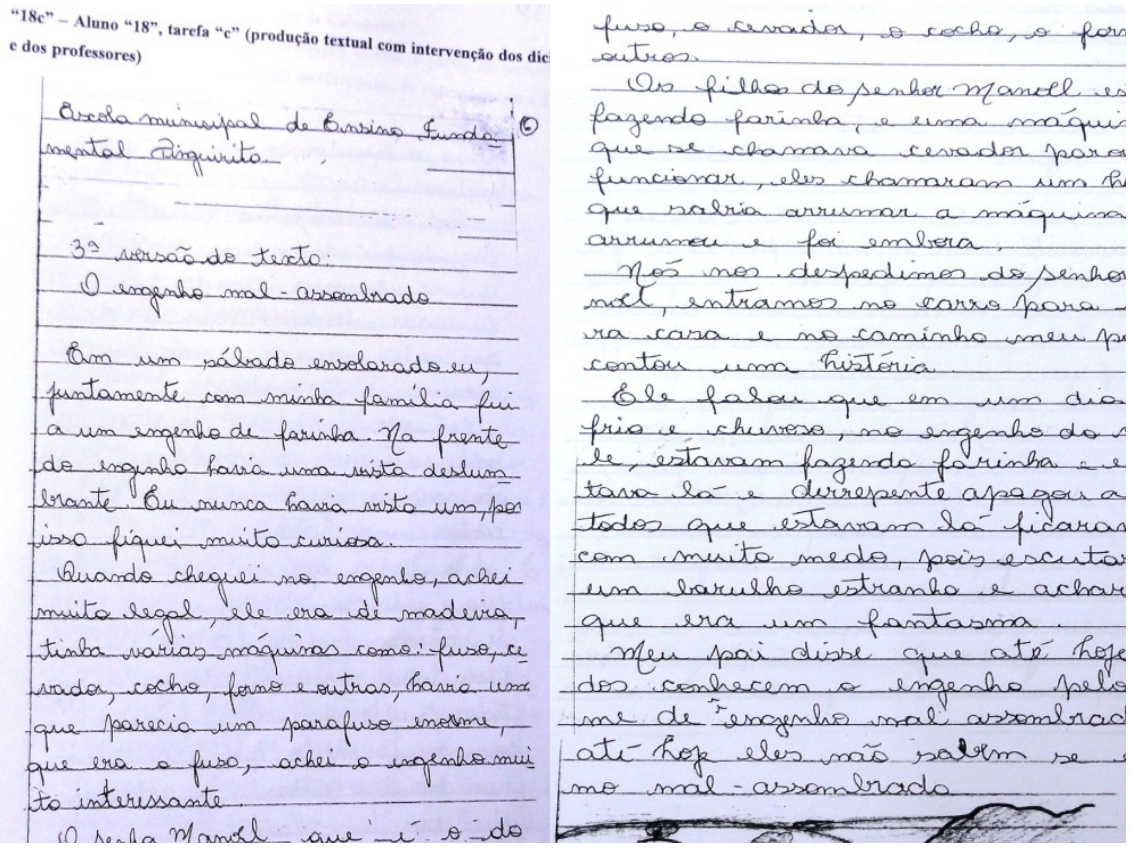

Nesta versão, o aluno foi muito atento à orientação escrita dos professores e às melhorias do texto e parece ter consultado um dicionário para se inteirar da grafia vigente na linguagem padrão.

O aluno melhorou a pontuação, e a leitura se tornou mais fácil do que nas duas versões anteriores; apenas poucas vírgulas foram usadas nos lugares em que não deveriam estar, e outras faltaram nos lugares adequados. Também houve melhora na estrutura de parágrafos, pois o aluno conseguiu escrever seis parágrafos com sentido, além de acrescentar palavras estudadas no texto-base, como "fuso", "forno", "cevador", "cocho", "deslumbrante".

Quanto à linguagem utilizada no texto, continua a ser a padrão, com exceção de “... foi muito legal”, uma expressão da gíria, e da palavra "derrepente", que ficou sem segmentação, o que demonstra insegurança desse discente quanto ao emprego padrão desse item lexical, já que nas outras versões estava de acordo com a linguagem formal.

Para uma criança com tenra idade (aproximadamente 11 anos), a escrita já se desenvolveu muito bem, com noções de sequência, conectividade e lógica, o que garante a progressão dos fatos narrados. No que se refere à estrutura da história, o aluno demonstra não ter desenvolvido essa ideia ainda, pelo menos por escrito. A sua história é relatada, mas não há um fato principal a ser resolvido, nem suspense para fascinar os leitores. Esse aspecto pode ser trabalhado com leitura de obras de ficção, por exemplo, chamando a atenção do aluno para o modo como os autores escrevem, com o objetivo de despertar a imaginação e proporcionar prazer aos leitores.

Trabalhou-se a escrita como um processo, assim, esses pontos precisam ainda ser desenvolvidos e praticados, ou seja, é preciso que o aluno perceba que, para se escrever melhor, é necessário um investimento de tempo, dedicação, leitura e pesquisa nos dicionários, para que se conheça mais sobre a linguagem empregada em uma situação formal. Precisa-se usar instrumentos didáticos que estão à disposição na sociedade, que se encontram nas escolas e universidades, para que eles se tornem úteis para os fins desejados de uma escrita mais incrementada. Também é preciso fomentar a formação de professores na área da Lexicografia e Metalexicografia, para que os dicionários se tornem instrumentos didático-pedagógicos com funções no processo de ensino-aprendizagem. 
Após três versões, esse aluno conseguiu se deixar guiar pelas intervenções dos dicionários, colega e professores, incrementando seu texto, quer com um vocabulário diferente da primeira versão, quer com a melhoria da conectividade entre as ideias, fazendo com que o texto se tornasse mais inteligível ao leitor.

Quanto às dificuldades enfrentadas pela criança nesse processo, os chamados "erros" são considerados construtivos, ou seja, são indicadores do processo de construção do sistema de escrita que a criança está vivendo. O professor analisará a produção do aluno e avaliará em que estágio do processo de apropriação da linguagem os alunos estão para, depois, explicar a eles a necessidade de um trabalho intenso para se passar, por exemplo, de uma linguagem menos formal para uma mais formal. Nesse trabalho, torna-se um desafio para o professor e para o aluno introduzir os dicionários como representantes de uma linguagem formal que pode interagir com escritores-leitores.

\section{CONSIDERAÇÕES FINAIS}

Os objetivos da pesquisa concretizaram-se, por exemplo, no texto do aluno "18" do GE, quando houve o uso do vocabulário estudado ao longo da arquitetura dos textos, como "fuso", "forno", "cevador", "cocho" e "deslumbrante".

Além disso, foi assegurada a continuidade dos textos pelo uso de expressões de tempo, como "Em um sábado ensolarado" e "Quando cheguei", além do acréscimo de detalhes, como descrição maior do lugar e personagens. O texto do aluno "18" serviu como exemplificação. Com relação aos demais textos do GE, com exceção de dois alunos, números " 8 " e "9", que apresentaram maior dificuldade nas tarefas propostas e que demonstraram isso nas versões escritas, os demais alunos (23) progrediram na forma e no conteúdo de suas produções textuais, comparando todas as três versões produzidas pelos alunos, da primeira até a última. ${ }^{10}$ Essa constatação fez com que se atingisse o objetivo de propor o uso de dicionários escolares de forma sistematizada, como instrumento didático-pedagógico que contribui para o incremento das produções textuais escritas, em termos de vocabulário, ortografia, entendimento da significação das palavras e de seu emprego em contexto. Não se trata de usar dicionários ao acaso, mas como um instrumento pedagógico de trabalho permanente da linguagem que recebe influências dos pesquisadores, bem como também exerce essa força.

O processo de expansão do vocabulário dos alunos pode demorar mais para uns ou menos para outros. No caso desta pesquisa, perceberam-se os diferentes ritmos de aprendizagem. As amostras de textos dos alunos revelam tal fato, quando houve um trabalho igual para todos, mas diferente na captação e entendimento de cada aluno, conforme o julgamento subjetivo de cada criança. De fato, uns progrediram mais, outros menos, com avanços, mas também com retrocessos, por envolverem-se fatores psicológicos, cognitivos e motivações distintas, como dedicação e interesse.

Por fim, também estão envolvidos fatores sociais representados no trabalho pelas interações entre alunos/alunos, alunos/professores, alunos/textos, alunos/dicionários, que contribuíram para que se construíssem processos significativos que norteiam o desenvolvimento do acervo lexical e que passam pela escrita e reescrita.

Processos significativos passam por essa crítica mais consciente dos textos e dos benefícios que um dicionário traz para a vida escolar e em sociedade, quando passamos a explorá-lo sistematicamente com todo o seu potencial. Potencial que pode ser explorado em diferentes faixas etárias, começando no ensino fundamental, passando pelo médio e prosseguindo no superior.

Além disso, processos significativos envolvem uma concepção de linguagem em que haja interação humana. Com a linguagem, o falante age sobre o ouvinte, constituindo compromissos e vínculos. Esses vínculos também se estabelecem quando o interlocutor lê um texto e opina, participa com sugestões, com senso crítico sobre o texto do outro. Na verdade, se torna um texto constituído por várias visões de mundo: a_do autor, a da intertextualidade presente na produção, a do leitor, a do professor e a dos dicionários. A 10 A análise completa dos dados pode ser averiguada na tese (em processo de qualificação). 


\section{Extensio $\mid$ Dossier}

imagem de que é preciso se chegar a um produto final, redigido sem preparação, entregue ao professor para ser corrigido e avaliado, cede lugar a um instrumento passível de mudanças por meio de muitas influências.

O uso do dicionário, nesta pesquisa, foi proposto como uma ferramenta que pode acelerar a aquisição lexical de quem começa a utilizá-lo. Com essa aquisição, inicia-se a etapa do uso dessa linguagem adquirida em contexto, momento em que as produções textuais entram no processo. Elas serão lidas por interlocutores compromissados com o autor e com a linguagem escrita. Voltando para seus autores, essas produções serão influenciadas pelos dicionários, os quais exercerão uma participação ativa para melhorar ainda mais o que já havia sido escrito, pela reescrita. Nessa sucessão de influências e reescritas, constituem-se os processos significativos que farão a diferença para que os alunos desenvolvam mais seu acervo lexical e, com isso, adquiram mais vocábulos para serem empregados na fala ou na escrita.

O saber democrático que existe nas obras lexicográficas ainda não atingiu as escolas e tende a não atingi-las, se persistirem as metodologias que as excluem da vivência da sala de aula. Fazer com que os estudantes conheçam dicionários, manuseiem suas páginas, descubram que há, inclusive, aprendizagem lúdica quando se trabalha com obras assim continua sendo um desafio muito grande para os educadores. As obras lexicográficas ainda passam à margem do processo de escrita e reescrita no ambiente escolar. ${ }^{11}$

Demos um passo em um panorama de reflexão sobre o uso de dicionários escolares em textos. A Lexicografia e o ensino de línguas podem ser beneficiados com o uso do dicionário em sala de aula, isto porque, com um trabalho permanente com essas obras, poderá haver discussões e descobertas sobre elas, resultando em seu maior controle de qualidade por parte do governo e das editoras. Dessas críticas e sugestões, novas obras poderão ser produzidas, mais adequadas didática e pedagogicamente às diferentes faixas etárias dos alunos. Além disso, pela viabilização e desenvolvimento de uma prática que aborde os dicionários na escrita e na reescrita de textos e pela interação entre alunos, professores e instrumentos didáticos, haverá a possibilidade de se escrever com mais propriedade, possibilitando aos alunos o domínio da norma padrão de forma mais significativa.

\section{REFERÊNCIAS}

COROA, Maria Luiza. Para que serve um dicionário? In: CARVALHO, Orlene Lúcia de Sabóia; BAGNO, Marcos. (Org.). Dicionários escolares: políticas, formas \& usos. São Paulo: Parábola, 2011, p. 61- 72 .

GERALDI, João Wanderley. (Org.). O texto na sala de aula: leitura \& produção. 2. ed., Cascavel: Assoeste, 1984.

LEFFA, Vilson José. O dicionário deveria ser sistematicamente utilizado em aulas de língua materna ou estrangeira como instrumento pedagógico? In: XATARA, Cláudia; BEVILACQUA, Cleci; HUMBLÉ, Philippe. (Org.). Dicionários na teoria e na prática: como e para quem são feitos. (Estratégias de Ensino, 24). São Paulo: Parábola Editorial, 2011, p. 123-124.

PCN. BRASIL. Ministério da Educação. Parâmetros Curriculares Nacionais: língua portuguesa. Ensino de primeira à quarta série. Brasília: Secretaria da Educação Fundamental, 1997. Disponível em: http://portal.mec.gov.br/index.php?option $=$ com content $\& v i e w=$ article\&id $=12640 \% 3$ Aparametroscurriculares-nacionais1o-a-4o-series \&catid=195\%3Aseb-educacao-basica\&Itemid=859. Acesso em: $12 / 12 / 2010$.

KRIEGER, Maria da Graça. O dicionário de língua como potencial instrumento didático. In: ISQUERDO, Aparecida Negri; ALVES, Ieda Maria. (Org.). As ciências do léxico: lexicologia, lexicografia,

11 Isto pode ser constatado em um capítulo da tese da doutoranda, intitulado "Curso de formação para professores sobre o uso de dicionários escolares em sala de aula". 
terminologia. Campo Grande: Ed. UFMS; São Paulo: Humanitas, 2007, v. 3, p. 295-309.

. Políticas públicas e dicionários para escola: o programa nacional do livro didático e seu impacto sobre a lexicografia didática. XATARA Cláudia; HUMBLÉ Philippe. (Org.). Cadernos de tradução. Tradução e lexicografia pedagógica. Florianópolis, v. 18, p. 235-252, 2006.

WELKER, Herbert Andréas. Panorama geral da Lexicografia pedagógica. Brasília: Thesaurus, 2008. . O uso de dicionários: panorama geral das pesquisas empíricas. Brasília: Thesaurus, 2006. 